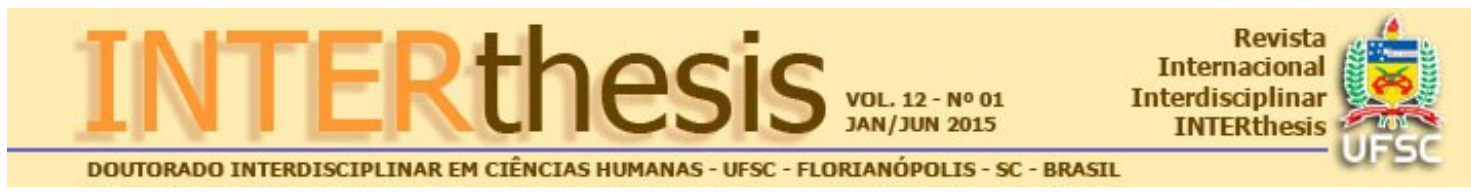

\title{
A ÉTICA ECOFEMINISTA DE KAREN J. WARREN: UM MODELO DE ÉTICA AMBIENTAL GENUÍNA?
}

Daniela Rosendo ${ }^{1}$

Tânia Aparecida Kuhnen²

\begin{abstract}
Resumo:
Karen J. Warren apresenta uma proposta ética ecofeminista, segundo a qual os contextos precisam ler levados em consideração na análise de situações e problemas morais, rejeitando-se o monismo ético das correntes principais de ética animal. O objetivo deste artigo é mostrar, à luz da noção de vulnerabilidade, critério de considerabilidade moral proposto por Paul Taylor, que a ética sensível ao cuidado de Warren pode não ser considerada uma ética ambiental genuína, à medida que se aproxima do biorregionalismo de Gary Snyder e não esclarece de que forma a consideração moral é atribuída aos animais individualmente. Quanto ao relativismo, segundo os critérios de James Rachels e Peter Singer, a proposta de Warren parece não cumprir com os requisitos de uma ética imparcial e geral, e pode incorrer nos problemas do relativismo, uma vez que a concepção de cuidado da autora é limitada.
\end{abstract}

Palavras-chave: Biorregionalismo. Cuidado. Ética ambiental. Filosofia ecofeminista. Relativismo moral.

\section{INTRODUÇÃO}

Com o surgimento da filosofia feminista na década de 1970, enquanto área de conhecimento organizada nos EUA, diversas teóricas feministas passaram a realizar uma leitura crítica da história da filosofia, supostamente comprometida com a sociedade patriarcal e a consequente desvalorização e exclusão das mulheres. Em diferentes campos da filosofia, filósofas e filósofos feministas passaram a reescrever a história sob o olhar feminista, contribuindo para a expansão da filosofia por meio de novos temas até então não debatidos ou mesmo através de um novo olhar sobre teorias tradicionais, procurando salvá-las dos limites de gênero e das afirmações generalistas sobre a humanidade que nunca consideraram a condição de opressão

\footnotetext{
${ }^{1}$ Doutoranda em Filosofia pela Universidade Federal de Santa Catarina. Mestre em Filosofia, área de ética e filosofia política, pela Universidade Federal de Santa Catarina. Professora da Associação Catarinense de Ensino e membro do Comitê Latino Americano e do Caribe para Defesa dos Direitos da Mulher. E-mail: daniela.rosendo84@gmail.com

2 Doutora em Filosofia pela Universidade Federal de Santa Catarina. Realizou estágio de pesquisa na Humboldt Universität zu Berlin. E-mail: taniakuhnen@hotmail.com
} 
das mulheres. Um dos campos que merece especial atenção nesse contexto, uma vez que se constitui em uma instância frutífera do pensamento filosófico feminista, é o da teoria moral feminista, a qual, por sua vez, tem como um de seus principais expoentes a ética do cuidado.

Embora a ética feminista seja caracterizada por diferentes teorias que têm como ponto de vinculação a crítica à filosofia moral tradicional, é a ética do cuidado, iniciada na década de 1980, por meio da obra de Carol Gilligan, In a Different Voice, que resultou em diversos desdobramentos inclusive no campo de reflexão da filosofia política, bem como em abordagens distintas em termos de teorias morais. Merecem destaque as contribuições originárias de Nel Noddings, Annette Baier, Virgínia Held, Marilyn Friedman, Eva Feder Kittay, entre outras. Apesar das divergências teóricas entre tais autoras, é consenso entre elas que muitos aspectos das relações morais ficaram de fora ao longo da história da filosofia moral e que o cuidado precisa ter lugar nas teorias éticas.

O discurso da ética do cuidado deparou-se também com as reformulações da ética tradicional que visam à expansão da comunidade moral para além de seres humanos, originando, através desse embate, a perspectiva ecofeminista. As teóricas ecofeministas argumentam, de forma geral, que há uma ligação entre a opressão e a exploração das mulheres, dos animais e da natureza. Com fundamentos diferentes, mostram que a linha de argumentação tradicional da ética baseada em princípios, não é suficiente para o fim da exploração, justamente porque diferentes sistemas de exploração estão imbricados e somente a partir do reconhecimento dessa relação é possível combatê-los. Por isso, a filosofia ecofeminista visa desconstruir os dualismos de valor, de origem cartesiana, que promovem as divisões que perpetuam a desvalorização das mulheres e da natureza.

Ecofeministas em geral chamam também a atenção para o fato de que alguns grupos são mais afetados pela crise ambiental. Esses grupos são justamente aqueles que tradicionalmente sofrem com outras crises, como a econômica, isto é, os que se encontram de forma permanente em situação de opressão e exploração. A natureza é devastada e os animais são explorados pela mesma lógica discriminatória e exploradora que vê certos grupos de humanos, e os não humanos, como meros objetos.

A partir da ótica feminista, Karen J. Warren avalia as éticas animalistas mais R. Inter. Interdisc. INTERthesis, Florianópolis, v.12, n.1, p.16-41, Jan-Jun. 2015 
conhecidas, como as de Peter Singer e Tom Regan, e argumenta que tais propostas não são suficientes para superar a dominação que os humanos exercem sobre os não humanos, uma vez que estão comprometidas pela suposta neutralidade de gênero, isto é, pelo problema que a história da filosofia enfrenta ao comprometer-se, ainda que apenas implicitamente, em grande medida com os pressupostos de uma sociedade patriarcal. Para Warren, existe uma lógica de dominação que vincula conceitualmente todas as formas de opressão, seja em relação às mulheres, ao gênero, à natureza, à raça etc. Assim, enquanto o feminismo visa abolir de forma central e primordial o machismo, o ecofeminismo procura ir além e vislumbra a abolição de todas as formas de discriminação, ou seja, do machismo, do heterossexismo, do racismo, do especismo etc. Por isso, é essencial pensar a discriminação sistemática de mulheres nas teorias morais juntamente com a exploração e desvalorização dos animais.

Warren defende que é necessária uma reformulação do feminismo para que ele vise também à libertação dos não humanos. Além da libertação das mulheres, é preciso libertar todos que sejam subjugados pelos sistemas de dominação. Por outro lado, as éticas ambientais também devem considerar moralmente os humanos que estão em situação de vulnerabilidade e que também sofrem as consequências da exploração da natureza. Para Warren, esse reconhecimento só é possível em uma ética que reconheça outros valores, além dos princípios racionais, das regras e dos direitos. O cuidado e a amizade, nesse sentido, devem ser eticamente relevantes.

A proposta de ética sensível ao cuidado de Warren é fortemente permeada pela contextualidade, ou seja, os contextos nos quais se formula a ética devem ser considerados. Entretanto, Warren não formula uma nova ética ambiental, mas escolhe a ética da terra, de Aldo Leopold, como uma das bases ecológicas da filosofia ecofeminista. Warren ressalta que a ética sensível ao cuidado não é uma ética do cuidado nos termos em que tradicionalmente ela é formulada. Embora Warren concorde com as críticas que eticistas do cuidado formulam em relação a uma ética da justiça, a ética sensível ao cuidado reconhece também a importância de uma concepção baseada em regras e princípios. No entanto, Warren afirma que a moralidade é composta também por outros valores, comumente afastados da ética, mas que precisam ser incorporados em uma teoria moral abrangente, como é o caso do cuidado.

R. Inter. Interdisc. INTERthesis, Florianópolis, v.12, n.1, p.16-41, Jan-Jun. 2015 
Com base na abordagem teórica de Warren, o objetivo deste artigo é analisar se a ética sensível ao cuidado se constitui como uma ética ambiental genuína. Para tanto, examina-se o alcance e os limites de sua filosofia ecofeminista. Por alcance, entendem-se os aspectos positivos de sua proposta, ou seja, onde Warren realmente alcança o que propõe e, mais além, qual a sua contribuição para a construção teórica de uma filosofia ecofeminista que questiona e visa superar sistemas de opressão. Do outro lado, por limites, entendem-se os pontos nos quais Warren não avança, seja por silenciar ou por tecer considerações que não se mantêm coerentes com sua teoria ou com uma proposta ética genuína. ${ }^{3}$

Nesse movimento, a proposta de Warren será analisada à luz da filosofia política ambiental, especialmente a partir do biorregionalismo de Gary Snyder, como marco teórico a partir do qual se pode avaliar o alcance e os limites. Procura-se estabelecer uma ponte entre o pensamento moral de Warren e as implicações políticas de sua proposta. Ademais, por se tratar de uma abordagem que sugere valorizar expressamente o contexto das decisões morais, será analisada também sob o viés do relativismo cultural.

\section{FILOSOFIA POLÍTICA AMBIENTAL E FILOSOFIA MORAL DE WARREN}

Ao apresentar as concepções filosóficas ambientalistas, Leon Farhi Neto (2006, p. 33) explica que existem diferentes propostas que se coadunam com a filosofia política ambiental. Segundo o autor, essas abordagens podem ser agrupadas em três rubricas: ambientalismo liberal, libertário e socialista. O ambientalismo liberal é expresso também por três correntes: 1) ambientalismo de mercado-livre de Terry L. Anderson e Donald R. Leal; 2) ambientalismo de mercadoverde de Paul Hawken; e 3) ambientalismo liberal de Avner de-Shalit. O ambientalismo libertário, por sua vez, é representado por duas propostas: 1) ambientalismo radical de Christopher Manes; e 2) biorregionalismo de Gary Snyder. Por fim, o ambientalismo socialista se expressa também por duas correntes: 1)

\footnotetext{
${ }^{3}$ A exposição da ética sensível ao cuidado e uma análise mais extensa de seu alcance e limites pode ser lida em ROSENDO, Daniela. Ética sensível ao cuidado: alcance e limites da filosofia ecofeminista de Warren. Florianópolis, 2012. 153 f. Dissertação (Mestrado em Filosofia) - Centro de Filosofia e Ciências Humanas, Universidade Federal de Santa Catarina. Disponível em: https://repositorio.ufsc.br/bitstream/handle/123456789/103388/314919.pdf?sequence=1. Acesso em: 8 abr. 2015.
}

R. Inter. Interdisc. INTERthesis, Florianópolis, v.12, n.1, p.16-41, Jan-Jun. 2015 
ecologia socialista de James O'Connor; e 2) ecologia social de John Clark.

Segundo Fahri Neto (2006, p. 34), a corrente de maior expressão atualmente é o ambientalismo liberal. Ao ressaltar que "o modo como cada corrente entende a dimensão da crise está diretamente relacionado com as mudanças que propõe", Fahri Neto explica que o ambientalismo de mercado-livre propõe soluções de mercado para as questões ecológicas, ao contrário do ambientalismo de mercadoverde, que embora acredite na solução de mercado, propõe que ele deve ser estruturado de forma diversa da atual. $\mathrm{O}$ ambientalismo liberal de-Shalit, por fim, supera a visão econômica de certo modo e propõe que a crise ecológica seja tratada na esfera política.

Fahri Neto conclui que as correntes liberais, conquanto não possam ser consideradas extremamente conservadoras, mantêm a estrutura político-econômica ocidental expressa por meio de "economias de mercado mais ou menos reguladas por Estados centrais, em grandes unidades geográficas." (FAHRI NETO, 2006, p. 40). Nesse sentido, pode-se questionar até que ponto tais concepções políticas de fato se comprometem com o meio ambiente ou constituem apenas uma estratégia de incorporação da questão ambiental ao próprio mercado. $O$ aspecto político local da questão ambiental parece não ser central, pois prevalece em meio a tais perspectivas a centralidade da manutenção da estrutura econômica corrente.

Distanciando-se da ideia de mercado, o ambientalismo libertário de Snyder (biorregionalista) e Manes (ambientalista radical) é caracterizado pelas novas formas de organização política das sociedades, inclusive em relação às questões ecológicas. Em síntese, explica o filósofo:

Podemos seguir os fundamentos de Snyder e dos biorregionalistas ao longo de duas séries que se cruzam numa terceira. A primeira série de fundamentos procura pontuar a referência essencial da humanidade à experiência do lugar. A segunda, articula-se em torno da crítica às estruturas centralizadoras dos Estados modernos. E, no cruzamento das duas, a terceira série se constrói, ou reconstrói, a concepção de biorregião, suporte do qual emergem as propostas biorregionalistas (FAHRI NETO, 2006, p. 40).

Na concepção de Snyder, o lugar faz parte do modo de ser, de forma que a percepção que se tem de si é construída simultaneamente pela experiência que se tem do entorno, do qual não é possível se dissociar. O próprio corpo expressa características do ambiente geográfico (relevos, depressões, asperezas), além da própria linguagem que reflete as expressões e pronúncias que marcam o lugar. 
Dessa forma, o lugar torna-se mais do que mero espaço e constitui as próprias condições de possibilidade e experiência do ser humano.

Segundo Fahri Neto (2006, p. 41), Snyder questiona também a ideologia do monoteísmo que, segundo ele, é uma ideologia formada por três princípios da modernidade: uniformização, universalização e centralização. A uniformização "torna igual o diverso, e todos os lugares, semelhantes", a universalização "refere o singular a algo mais geral, a que é atribuído um valor superior" e a centralização é a base "dos mecanismos de concentração de poder e riquezas". Dentro dessa linha de princípios da modernidade, Snyder critica veementemente a formação do Estado que, para ele, não produz paz nem justiça. Ao contrário, é justamente a forma de organização dos Estados nacionais que causa a destruição ambiental e gera a guerra entre os seres humanos, por ignorar aspectos regionais e locais e uniformizar a todos sob a ideia de nação unificada. Assim, Snyder propõe a ideia de biorregião, que se caracteriza basicamente por dois aspectos: território e cultura, estando ambos vinculados um ao outro. Nesse conceito, portanto, vinculam-se tanto os aspectos físicos e geográficos (espécies de plantas, condições climáticas etc.) quanto a unidade política descentralizada, que rompe com a concepção de Estado nacional (FAHRI NETO, 2006, p. 41).

O ambientalismo radical de Manes, também um ambientalismo libertário, caracteriza-se pelo uso da ação direta na defesa do ambiente físico natural e das espécies vivas, por meio da desobediência civil, da ecotagem e da ecossabotagem, que Manes diferencia do ecoterrorismo (FAHRI NETO, 2006, p. 42-43).

O último modelo de ambientalismo é o socialista, cujas propostas advêm de James O'Connor (ecologia socialista), estando associado ao movimento socialista, e de John Clark (ecologia social), que se aproxima dos comunitaristas da filosofia política. Para O'Connor, não é possível dissociar a crise ecológica do modelo econômico e político (FAHRI NETO, 2006, p. 45).

Apesar de tanto o ambientalismo radical de Manes quanto o ambientalismo socialista de Clark e O'Connor romperem com a tradicional visão da primazia do desenvolvimento econômico, é o fato de o biorregionalismo de Snyder ser marcado pela descaracterização do Estado nacional e a consequente valorização da região geográfica e suas características físicas e sociais que possibilita sua aproximação da proposta de Warren. A filósofa ecofeminista não aborda a constituição do Estado, 
uma vez que sua proposta está centrada no desenvolvimento de uma teoria moral, mas reiteradamente afirma que os contextos precisam ser observados, incluídos os aspectos geográficos, físicos e sociais. Isso significa que sua teoria moral não pode ser desvinculada de implicações políticas e da necessidade de mudanças em termos de organização social.

Snyder (1999, p. 196-197), por sua vez, é claro em relação a sua filiação política anarquista. Para o autor, as regiões são anárquicas, sendo o local onde se vive que determina quem somos, pois é nele que são formadas as percepções e os conceitos de vida. Por valorizar as características ambientais da região, que não respeitam as fronteiras nacionais, a organização política deve respeitar a orientação e subordinação biogeográfica, na qual todas as formas de vida e o tempo da natureza sejam respeitados. Nesse contexto, o conceito de Commons aparece como central na proposta de Snyder (1999, p. 187) e representa "o contrato que um povo faz com seu sistema natural local", permitindo resgatar a tradição asiática, europeia e dos povos americanos. Em consonância com esse entendimento, Snyder (1999, p. 191-192) propõe que o uso de terras seja comunitário, sem intervenção estatal, e critica as fronteiras artificiais dos Estados-nações, impostas de forma violenta por desconsideram a biorregião. São os habitantes da região que a conhecem e têm capacidade para administrá-la.

Embora Warren não se posicione claramente acerca de sua posição política, quando afirma que as perspectivas locais ou indígenas são condição sine qua non para a constituição da filosofia ecofeminista, ao lado do feminismo, da natureza, da ciência, do desenvolvimento e da tecnologia, acredita-se que ela se aproxime da proposta biorregionalista. Além disso, ainda que Warren não se situe em relação ao nível de interferência estatal, como fazem as propostas ambientalistas vistas acima, Warren é enfática, ao longo de toda a sua construção teórica, ao afirmar que o "contexto" é sempre fundamental na análise de sua teoria. Mesmo que a motivação de Warren seja a consideração das especificidades e particularidades do contexto para analisar situações e problemas morais, essa perspectiva implica também em compromissos políticos quando a vida de animais e o meio ambiente conflitam com interesses econômicos preponderantes e definidos por políticas de Estado nacional. Esse é um ponto que aproxima Warren novamente de Snyder, uma vez que é possível considerar esse contexto não somente pelos elementos específicos e 
relações singulares que se formam no ambiente cultural, mas também na esfera geográfica. Para Snyder (1999, p. 183), o local deve ser visto como uma experiência que não pode se esmaecer em nome de objetivos e finalidades de âmbito nacional. De uma forma ou outra, o aspecto político e o ético se cruzam na abordagem situada pelo contexto. Relações morais implicam também certas condutas políticas, ou seja, o modo como em determinados contextos são expressas as relações morais entre seres humanos e animais, ou mesmo mulheres e animais, tem consequências sobre a forma como o político e o econômico, em consonância com as características geográficas, são constituídos nesse mesmo local.

Tendo por base a aproximação que se pode realizar entre a perspectiva ética contextual de Warren e o ambientalismo regional de Snyder, importa analisar em que medida tais concepções vinculadas a aspectos contextuais constituem genuinamente uma ética ambiental. Um dos parâmetros relevantes para essa avaliação é o do estabelecimento de critérios de considerabilidade moral, que podem variar de acordo com a perspectiva ética adotada.

Sônia T. Felipe afirma que, em virtude da tradição moral vigente, vive-se uma trilemia moral: cada vida (vegetal, animal não humana ou humana) é valorada de forma diferente. No entanto, Felipe afirma que a configuração biológica e a aparência exterior do ser vivo não devem ser relevantes para sua valoração. "O corpo não é a causa da vida. Ele é a configuração específica na qual a vida mesma se expressa." (FELIPE, 2006, p. 106). Assim, Felipe afirma que, no esforço para superar essa perspectiva hierárquico-antropocêntrica, na qual a vida humana tem mais valor do que as demais, teóricos éticos críticos propõem outros critérios de considerabilidade moral: a vida (Kenneth Goodpaster), a interdependência biótica (Aldo Leopold), a autonomia prática ou a liberdade de mover-se para prover-se de acordo com sua espécie (Peter Singer) e a vulnerabilidade ou o valor inerente (Tom Regan). "A adoção de qualquer desses critérios propostos acima, implica na redefinição da ética tradicional." (FELIPE, 2006, p. 107).

A partir da crítica de Tom Regan e Paul Taylor aos critérios de considerabilidade moral, Felipe avalia os limites do critério da vida proposto por Goodpaster. Para os autores, existem pelo menos quatro deveres na ética: negativos, positivos, diretos e indiretos. A liberdade dos sujeitos morais, dessa forma, é limitada pelo reconhecimento de cada um desses deveres a outros sujeitos 
morais (mesmo que eles sejam "sujeitos morais naturais"). Nessa senda, Regan e Taylor criticam que no sentido que Goodpaster confere à vida, como critério ético universal, geral e imparcial, deve-se reconhecer que há deveres morais positivos, tanto quanto há negativos, de proteção, assistência e não-maleficência, o que acaba por engessar a proposta, em decorrência de uma responsabilidade moral absoluta que vai além da preservação da vida, mas também pela promoção do bem-estar de todas as espécies vivas (FELIPE, 2006, p. 108).

Para Regan, o critério da senciência proposto por Singer também é limitado, visto que as condições necessárias para que a vida seja expressa plenamente pelo sujeito moral podem ser limitadas, mesmo sem causar-lhe dor. Atendo-se a esse aspecto limitador, Taylor elege a vulnerabilidade ligada ao bem inerente de cada vida individual como critério para propor uma ética ambiental genuína. A vulnerabilidade indica que um ser tem a condição de poder sofrer as consequências das ações de um sujeito moral racional, ou seja, de um agente moral, mesmo que somente na posição de paciente moral. Não é mais a vida que inclui os sujeitos no círculo de consideração moral, mas o fato de poderem ser prejudicados de diferentes modos na forma de vida que lhes é própria pelas ações de sujeitos morais. A partir desse critério da vulnerabilidade, tanto animais não humanos quanto ecossistemas podem ter seus interesses preservados (FELIPE, 2006, p. 109).

Taylor salienta que qualquer ser vivo possui um bem que lhe é próprio [good of its own], ou seja, uma forma específica de existência e de auto-realização e pode ser prejudicado na realização desse bem. Para poder dizer que uma entidade tem um bem que lhe é próprio, é necessário ter sentido falar do que é bom ou mau para ela, sem se referir a qualquer outra entidade ou coisa (TAYLOR, 1989, p. 61). Por ter um bem próprio, cada coisa viva tem também um "bem inerente" [inherent worth] enquanto centro de vida singular e teleológico (TAYLOR, 1989, p. 75). Por isso, deve-se ter uma atitude de respeito às formas de vida da natureza, promovendo-se e protegendo-se o bem próprio de cada entidade individual, independentemente de sua contribuição para a comunidade biótica ou para um ecossistema, ou mesmo de sua utilidade e vinculação a determinadas populações regionais.

O valor moral de uma vida individual dentro da concepção teórica de Taylor não depende do modo como se configuram em relações contextuais e regionais com seres humanos, mas por se constituírem em formas de vida que buscam seu próprio 
bem a seu próprio modo. Em outras palavras, na perspectiva biocêntrica de Taylor, o dever moral de respeitar a natureza não decorre da necessidade de seres humanos usufruírem dos ecossistemas no futuro para terem seu bem-estar promovido e protegido, e sim porque plantas e animais possuem um bem próprio, o qual, com base na aceitação de um sistema ético normativo válido, motiva uma atitude racional de respeito à natureza.

Para analisar, então, o alcance o os limites do biorregionalismo, Silvio Luiz Negrão (2006) retoma a argumentação de Snyder à luz dos critérios estabelecidos por Goodpaster e Regan. Segundo Negrão, o biorregionalismo, nos termos em que é proposto por Snyder, não pode ser considerado uma ética ambiental genuína, pois não cumpre as exigências da universalidade, generalidade e imparcialidade e, por conseguinte, não elege e estrutura uma proposta ética a partir de um critério de considerabilidade moral. Um critério de considerabilidade é essencial para que, a partir dele, seja possível estabelecer de que modo as ações devem ser realizadas para que sejam morais para além dos limites contextuais e culturais, isto é, que possam ser universalizadas, generalizadas em todas as situações semelhantes e que não priorizem certas vidas em detrimentos de outras.

Além do critério da vulnerabilidade ligado à possibilidade de prejudicar ou proteger o bem próprio individual de animais e plantas, Taylor estabelece os parâmetros ou condições para validar os princípios normativos de uma bioética ambiental genuína, quais sejam: a) devem ser gerais na forma, sem referência a pessoas ou condições particulares; b) devem poder ser universalmente aplicáveis por todos os agentes morais como tais; c) devem pretender ser aplicados de forma desinteressada, sem que se pretenda obter vantagens sobre outros ou outras formas de vida; d) devem ser defendidos como princípios normativos por todos os que os adotam; e e) devem ser tomados acima de todas as normas não morais. (TAYLOR, 1989, p. 27-31).

Importa salientar que mesmo a adoção de um sistema ético com reivindicações universais, gerais e imparciais não implica a desconsideração de contextos e especificidades regionais na resolução de problemas. A diferença é que a motivação para a moralidade e a proteção para além da vida humana, não deriva das configurações regionais, culturais e biológicas; mas o sistema ético normativo é anterior e se sobrepõe às variações e especificidades biorregionais.

R. Inter. Interdisc. INTERthesis, Florianópolis, v.12, n.1, p.16-41, Jan-Jun. 2015 
Ao colocar em primeiro plano o papel dos povos em relação às biorregiões, sem considerar parâmetros ou um conjunto de regras anterior e que vá além das especificidades contextuais e regionais, Snyder fere as exigências normativas da universalidade e da generalidade. $\mathrm{O}$ autor biorregionalista também parece dar valor preponderante ao tipo de relações configuradas nas regiões, e não ao bem próprio das vidas humanas e não humanas consideradas individualmente.

Negrão (2006, p. 186) afirma, também, que o critério da vida estabelecido por Goodpaster é inadequado para a concepção biorregionalista, uma vez que não orienta de que modo esse critério abrangente poderia ser combinado com as necessidades e particularidades regionais. Se aos povos tradicionais é atribuída a capacidade de resolver os dilemas morais oriundos de conflitos entre duas ou mais vidas que competem entre si com base no critério da vida, que não oferece regras de distinção entre diferentes formas de vida de acordo com a possibilidade de sua vulnerabilidade ou de serem prejudicados ou protegidos em suas formas específicas de vida, torna-se inviável escolher entre uma vida ou outra. O critério levaria ou a uma espécie de inação moral, ou a uma decisão autoritária, interessada e arbitrária. O que falta é um princípio ou conjunto de regras que vá além da perspectiva cultural e regional e considere o bem próprio de cada vida individual igualmente.

Analisando o biorregionalismo à luz do critério de Regan, Negrão (2006, p. 187-188) afirma que Snyder reconhece o valor inerente dos povos nativos, dos membros de uma comunidade e de suas biorregiões, pois a ambos reconhece a considerabilidade moral, de forma análoga ao que faz Regan com as vidas individuais de sujeitos de uma vida. No entanto, por considerar o ambiente uma fonte de recursos naturais, diante de um conflito a decisão que deve ser tomada pelos povos pode se revelar marcada pela parcialidade, eis que todos os envolvidos são reconhecidos pelo seu valor inerente e, consequentemente, a decisão pode ser tomada a partir da avaliação do impacto do conflito, ou seja, de uma avaliação de qual sujeito tem seu valor inerente mais evidente, ou ainda uma avaliação na qual o valor inerente da vida individual termina por ser subsumido àquilo que é mais importante subjetivamente para a população local.

No esforço para transpor essa avaliação à proposta de Warren, pode-se inferir que ela também tem limitações em relação ao critério de considerabilidade moral para a constituição de uma ética ambiental genuína. Se Warren comunga 
alguns ideais biorregionalistas, ainda que não de forma expressa, especialmente ao valorizar os povos e os contextos de cada região, ela também esbarra na aplicação do critério da vida e do valor inerente ao ter que resolver conflitos. Contudo, é necessário ressalvar que esse pode ser um problema oriundo da própria concepção do critério de considerabilidade moral (vida, valor inerente) e dos limites de sua aplicação prática. Ao mesmo tempo, Warren não assume então qual deveria ser o critério a ser adotado, que permitisse conciliar variações, particularidades e especificidades regionais com o sentido mais amplo de uma teoria moral normativa com validade universal.

Em sua proposta, Warren não deixa expressa sua filiação a qualquer desses critérios definidos por eticistas animalistas e ambientalistas. Ao contrário, ela critica tanto o utilitarismo de Singer, que adota o critério da senciência, quanto a teoria de direitos de Regan, baseada no valor dos sujeitos de uma vida, na defesa dos animais. Por outro lado, para dar o conteúdo ético ambiental à filosofia ecofeminista, Warren elege a ética da terra de Aldo Leopold, o qual termina por subsumir o valor de vidas consideradas individualmente a sua contribuição para o equilíbrio de comunidades bióticas e ecossistemas. Embora essa abordagem ética não seja objeto precípuo de análise nos estudos que aqui referidos, Callicott, ao se inspirar da abordagem holista de Leopold, claramente assevera que o valor das vidas individuais subsume-se ao de espécies, comunidades bióticas e ecossistemas. Assim, na solução de conflitos regionais, o valor de uma espécie, por exemplo, sobrepõe-se ao do indivíduo; o da espécie, por sua vez, é sobreposto pelo valor da comunidade biótica. Callicott sustenta que Aldo Leopold fornece "uma declaração concisa do que pode ser chamado de imperativo categórico ou preceito fundamental da ética da terra: 'Algo é correto quando tende a preservar a integridade, a estabilidade e a beleza da comunidade biótica. Algo é errado quando tende ao contrário"' (CALLICOTT, 1980, p. 320). Com isso, o valor moral da ação depende diretamente de seu efeito sobre o sistema ecológico. Essa concepção parece aproximar-se da perspectiva biorregionalista de Snyder.

As diferentes partes de uma comunidade biótica possuem, segundo Callicott, uma dependência "econômica" entre si para que o sistema se desenvolva como tal em suas especificidades, distinguindo-se dos demais. Cada um desses sistemas (comunidades bióticas, ecossistemas) exerce uma função específica e, por isso, 
deve ter sua integridade garantida, o que implica deveres de respeito que comprometam os agentes morais para com o todo. Os seres humanos não podem prejudicar a estrutura de sistemas unificados e interdependentes do mundo natural (CALLICOTT, 1980, p. 322). O problema dessa abordagem é que o bem próprio de um organismo individual só é reconhecido à medida que contribui para o equilíbrio de uma comunidade biótica como um todo. Caso contrário, não há razões moralmente relevantes dentro da perspectiva holista de Leopold e Callicott para preservar a vida individual.

Warren escolhe a ética da terra, de Leopold, como uma das bases da sua ética ecofeminista. Warren argumenta que Leopold é holista, pois os ecossistemas merecem consideração moral. Contudo, Warren pode incorrer no problema do holismo de valorizar o todo ao invés do indivíduo. Isso fica claro quando Warren denomina os animais, as florestas e a terra como "Outros terrestres". No mesmo conceito, Warren inclui seres sencientes e não-sencientes. Em nenhum momento Warren se propõe a trabalhar somente com a ética animal, mas a escolha da ética da terra como pressuposto da ética ambiental ecofeminista pode explicar por que ela não se posiciona sobre questões éticas relevantes em relação aos animais, como a experimentação animal, por exemplo, ou sua exploração para extração de produtos (ovos, leite, lã, mel etc.).

Ademais, ao fazer a distinção entre dominação e opressão, Warren afirma que não humanos não podem ser oprimidos, somente dominados, pois a opressão implica em impedir a liberdade de fazer escolhas. Warren pressupõe, assim, que animais não podem fazer escolhas, isto é, que sequer possuem uma autonomia em sentido prático à medida que escolhem o que comer, para onde se deslocar e como constituir seu grupo. Novamente, Warren deveria distinguir a partir de um critério moral animais, plantas, minerais e rios: animais, enquanto seres senscientes podem fazer certas escolhas, diferentemente de rios e minerais, e podem então ser prejudicados de formas muito mais complexas e danosas em seu bem próprio; ao contrário de rios e minerais que, segundo Taylor, não possuem um bem que lhes é próprio nem uma finalidade a ser alcançada para si e por si mesmos.

O holismo pode conduzir ao problema da indistinguibilidade entre as formas de vida. Plumwood alerta para a questão ao afirmar que embora seja necessário descontruir diversos dualismos, entre eles, o dualismo ser humano versus natureza, 
homem versus mulher, razão versus emoção, substituindo visões de diferenças oposicionais pela ideia de um continuum, não se pode, ao mesmo tempo, cair no risco da indistinguibilidade, como se todas as partes antes fragmentadas e opostas fossem agora a mesma coisa. Se uma visão da natureza que situa os seres humanos fora dela, adotando uma perspectiva de descontinuidade e colocando seres humanos como controladores externos resulta na exploração do mundo natural, uma perspectiva de continuum deve ater-se as inter-relações sem que se negue a individualidade dos sujeitos (PLUMWOOD, 1998, p. 298).

Dessa forma, afirmar as inter-relações e a não separação em esferas distintas não pode implicar a negação da individualidade e da diferença. Ao assumir meramente um processo unificador, no qual tudo é parte de algo maior, de um todo indistinguível, abre-se caminho para a invisibilidade das individualidades e das necessidades específicas da constituição de cada ser vivo (PLUMWOOD, 1998, p. 300-301). Com isso, uma visão profundamente integrativa nega qualquer especificidade da natureza dos diferentes seres.

Essa mesma indistinguibilidade está presente em muitas sociedades que atribuem o mesmo estatuto moral, ou a falta dele, a mulheres e animais, como se fossem partes indistinguíveis da natureza e instrumentos à disposição de grupos mais altamente situados na escala hierárquica da dominação. Não é uma perspectiva que permita, então, fazer uma crítica em relações a populações regionais que dispõem de mulheres e do meio ambiente para a exploração. A alegação de um continuum, portanto, não pode ser feita em detrimento do reconhecimento de distinções e diferenças com base em necessidades e independência entre diferentes formas de vida. O continuum é, antes, uma visão que visa rejeitar a hierarquia dessas diferenças, que faz dos grupos dominantes os verdadeiros representantes da natureza de sua espécie, legitimando-os a dominar e controlar a parte inferior, e apontar a relevância de se reconhecer cada ser com suas especificidades e particularidades que constituem sua identidade individual para que se possa respeitar a todas e todos igualmente por meio de uma atitude sustentada em uma ética normativa coerente.

Em suma, a abordagem de Warren, de forma análoga aos biorregionalistas, apesar de valorização das especificidades regionais e culturais, sofre da limitação de não dar conta da integração dessas variedades ligadas a populações regionais em 
uma sistema ético normativo com pressupostos universais, gerais e imparciais. Não fica estabelecido, então, como conflitos regionais e entre diferentes formas de vida devem ser resolvidos, isto é, qual critério de considerabilidade moral deve ser adotado e que tipo de valor se reconhece às vidas individuais: se seria o valor individual de cada vida em virtude do bem que the é próprio, ou se seria o valor da vida hierarquizado segundo sua contribuição para o bem de uma espécie, de uma comunidade biótica, de um ecossistema ou de uma população regional. A falta de especificação de todas essas condições dificulta a classificação de sua teoria como uma concepção ambiental genuína. Ademais, como se verá no item que segue, ao não tomar posição em relação a esses problemas, Warren abre margem para questionar em que medida sua proposta ética não é culturalmente relativista.

\section{A PROPOSTA ECOFEMINISTA DE WARREN EM MEIO AO RELATIVISMO} CULTURAL

A ética sensível ao cuidado, proposta por Warren, possui diversos pontos em comum com a abordagem mais tradicional da ética do cuidado, que se coloca como uma alternativa à ética de princípios universais, conquanto possua também características de uma teoria ética imparcial. Warren enfatiza que o contexto é sempre relevante na avaliação de problemas morais, o que leva a questionar se sua ética é ou não relativista. Neste item, essa análise será feita à luz das considerações de James Rachels e Peter Singer.

Partindo da afirmação de que diferentes culturas possuem diferentes códigos morais, Rachels (2006, p. 19) analisa o desafio do relativismo cultural. Segundo o filósofo, a estratégia de argumentação dos relativistas parte da discussão dos fatos, para avaliar as diferenças culturais, a fim de chegar, então, à moralidade. A medida da moralidade é, em última instância, conforme acrescenta Shafer-Landau (2012, p. 291), aquilo que cada cultura ou sociedade define como correto e errado. ${ }^{4}$

\footnotetext{
${ }^{4}$ Importa distinguir entre o relativismo cultural e o relativismo individual. No caso desse último, também referido como subjetivismo ético, tem-se que são moralmente corretos todos os padrões de ações endossados por cada indivíduo. Um ato seria moralmente aceitável meramente porque um sujeito o aprova. Os comprometimentos individuais são os princípios que tal sujeito apoia. Com isso, a convicção pessoal é a medida última da moralidade. No caso do relativismo cultural, os critérios últimos da moralidade são dados pelos comprometimentos de cada cultura. O que é moralmente correto é, então, relativo às culturas ou às sociedades (SHAFER-LANDAU, 2012, p. 291).
}

R. Inter. Interdisc. INTERthesis, Florianópolis, v.12, n.1, p.16-41, Jan-Jun. 2015 
Para Rachels, o argumento de que diferentes culturas possuem diferentes códigos morais e, portanto, não há verdade objetiva na moralidade, é falso. Não é possível deduzir uma conclusão sobre uma questão moral meramente a partir do fato de as pessoas discordarem sobre ela. "O ponto lógico é somente que a conclusão não resulta da premissa." (RACHELS, 2006, p. 21). Em outras palavras, não é porque sociedades discordam quanto a correção ou o erro de certos valores e ações morais que se pode inferir que não há padrões para definir o que é moralmente correto e errado e que, então, qualquer coisa que seja convencionada em qualquer sociedade ou cultura é moralmente justificável e válido.

Contudo, mesmo após rejeitar essa formulação mais simples do argumento das diferenças culturais, Rachels afirma que o relativismo cultural ainda pode ser verdadeiro. Assim, ele elenca três consequências de assumir o relativismo:

1. Não poderíamos dizer que os costumes de outras sociedades são moralmente inferiores aos nossos próprios. [...] 2. Poderíamos decidir se as ações estão certas ou erradas apenas por meio da consulta aos padrões de nossa sociedade. [...] 3. A ideia (sic) do progresso moral é posta em dúvida. (RACHELS, 2006, p. 21-22) (grifo do autor)

O primeiro argumento, se realmente levado a sério, implicaria na rejeição de qualquer prática social como imune a críticas. Isso pode se tornar problemático quando essas práticas envolvem questões que parecem ser erradas em "qualquer" sociedade, como o antissemitismo, por exemplo. O segundo argumento impede que os padrões de nossa própria sociedade sejam questionados sob a justificativa de que há neles algum equívoco ligado a preconceitos, à ignorância, ao pensamento superficial, à lavagem cerebral etc. Se o certo e o errado são relativos, isso deve se aplicar internamente também. Por fim, a ideia do progresso moral também é problemática, eis que segundo os preceitos do relativismo, os padrões sociais de uma época não podem ser utilizados para julgar os padrões de outra época. Assim, não há um critério a partir do qual seja possível avaliar o progresso. Por essas razões, o relativismo cultural continuou sendo negado por muitos pensadores (RACHELS, 2006, p. 22-23).

Ao se pensar no próprio movimento feminista, por exemplo, uma perspectiva relativista da moralidade não permitiria entender como a reivindicação de igualdade legal e de poder por parte das mulheres, representa um progresso da moralidade. 
Shafer-Landau (2012, p. 295) observa, todavia, que a redução gradual do racismo e do sexismo representam uma espécie de progresso moral, pois as ações morais tornam-se melhores do que eram e as próprias crenças morais parecem progredir no sentido de algo mais verdadeiro, elas mudam fundamentalmente para melhor.

No entender de Rachels (2006, 24-25), as diferenças entre as sociedades residem mais em seus sistemas de crenças do que propriamente em seus valores. Os valores são apenas um fator dos costumes de uma sociedade. Isso faz com que as divergências sejam menores do que elas aparentam. Dessa forma, os costumes podem diferir entre uma sociedade e outra em virtude das pressões que a vida thes impõem. Por exemplo, os esquimós aceitam, entre eles, a prática do infanticídio. Isso pode ser justificado pela limitação que a mãe tem de amamentar mais de um filho ou filha ao mesmo tempo (considerando que elas costumam amamentar por até quatro anos), a necessidade de manter um equilíbrio entre homens e mulheres, eis que são os homens que saem para caçar e, portanto, estão mais vulneráveis ao risco de morte etc. Se esses fatores forem levados em conta, o infanticídio não significa uma diferença fundamental na consideração da criança, pelo contrário, pode ser uma atitude necessária à sobrevivência da família.

Após essa avaliação, Rachels (2006, p. 26-29) pontua que, para que as sociedades existam, algumas regras morais devem estar presentes nelas. Um exemplo é o da proibição do assassinato. Somente as exceções a algumas regras podem variar de uma sociedade para outra, não as próprias regras. Assim, o critério para estabelecer a adequação de qualquer prática social pode advir do questionamento da prática social, ou seja, se ela promove ou impede o bem-estar das pessoas afetadas por ela. Nesse sentido, pelo menos algumas regras ou princípios morais precisam ter validade universal para se questionar práticas sociais tendo em vista o progresso moral.

À guisa de conclusão, Rachels pondera que mesmo apresentando os erros do relativismo, essa teoria ainda parece chamativa. Assim, o filósofo destaca duas lições que podem ser aprendidas com ela. Em primeiro lugar, é importante lembrar que nem todas as preferências são baseadas em um padrão racional absoluto. Nesse sentido, é fundamental diferenciar as questões morais das meras convenções sociais, que não devem ser classificadas como certas ou erradas, do ponto de vista moral. Em segundo lugar, Rachels alerta que é necessário manter a mente aberta 
para identificar quais os preconceitos das sociedades, a partir dos quais somos formatados. "Podemos vir a entender que nossos sentimentos não são necessariamente percepções da verdade - eles podem ser nada mais do que o resultado do condicionamento cultural." (RACHELS, 2006, p. 31-32)

Também ao abordar o tema do relativismo, Peter Singer afirma que um exemplo de teoria que visou combater o relativismo é o marxismo de Friedrich Engels, que afirma que embora a moralidade de uma sociedade seja sempre relativa à classe que the é dominante, pode haver uma sociedade sem classes com uma moralidade realmente humana, isto é, que há uma base moral para ir além do relativismo cultural. Singer afirma que as crenças e os costumes podem exercer forte influência, mas disso não decorre que as pessoas decidam sempre de acordo com eles. No mesmo sentido de Rachels, Singer afirma que o ponto de vista segundo o qual a ética é sempre relativa a uma sociedade tem consequências implausíveis, pois o relativismo não permite argumentar em torno de conflitos morais. A título de exemplo, Singer (2002, p. 13-14) menciona a escravidão: se uma sociedade a aceita e outra não, em uma análise relativista não há uma base a partir da qual se poderia afirmar o que é certo ou errado. "Para serem eticamente defensáveis, é preciso demonstrar que os atos com base no interesse pessoal são compatíveis com princípios éticos de bases mais amplas, pois a noção de ética traz consigo a idéia de alguma coisa maior que o individual." (SINGER, 2002, p. 18)

Nesse sentido, Singer defende a universalidade da ética. Para ele, embora muitos filósofos discordem entre si (Kant, Hare, Hume, Adam Smith, Bentham, Sartre e Habermas, por exemplo), algo de suas concepções os aproxima: "Todas concordam que a justificação de um princípio ético não se pode dar em termos de qualquer grupo parcial ou local" (SINGER, 2002, p. 19). O juízo ético deve superar preferências a aversões pessoais para que possa ser universalmente aplicável:

Ao admitir que os juízos éticos devem ser formados a partir de um ponto de vista universal, estou aceitando que os meus próprios interesses, simplesmente por serem meus interesses, não podem contar mais que os interesses de uma outra pessoa. Assim, a minha preocupação natural de que meus interesses sejam levados em conta deve - quando penso eticamente - ser estendida aos interesses dos outros. (SINGER, 2002,p. 20)

Singer (2002, p. 333) retoma essas questões quando, no último capítulo de Ética Prática, questiona por que se deve agir moralmente. Ele afirma que não se 
pode sustentar a universalidade dos juízos morais e, ao mesmo tempo, eleger os princípios éticos de uma determinada pessoa como predominantemente importantes, quando eles não poderiam ser universalizáveis. Singer conclui que se o objetivo é buscar uma vida com sentido, para além dos interesses pessoais, é necessário adotar um ponto de vista ético. Portanto, é preciso ultrapassar o ponto de vista parcial e adotar a imparcialidade: "ver as coisas eticamente é uma maneira de transcender as nossas preocupações subjetivas e de nos identificar com o ponto de vista mais objetivo possível" (SINGER, 2002, p. 351).

Diante do exposto, é necessário analisar se a ética sensível ao cuidado incorre, ou não, nos problemas do relativismo. Quando Warren defende sempre o contexto como fundamental e elenca o universalismo situado como uma das características da ética sensível ao cuidado, surge esse questionamento. Embora Warren (2000, p. 113) afirme que "a universalidade reside na particularidade", sua proposta não exclui os princípios éticos universais. O que ela nega é o monismo ético, quando um único valor é determinado como relevante para a análise e decisão moral. Assim, os princípios se mantêm universais, mas Warren amplia o rol e inclui valores como o cuidado e sua importância para a manutenção de relações com outro sujeito à moralidade, por exemplo. Isso, em princípio, não torna Warren uma relativista cultural: se os princípios são os mesmos, cada situação demandará a escolha de um deles como o melhor, a ser aplicado de um determinado modo em um caso específico. Além disso, a validade de um princípio universal pode ser mantida ainda que situações particulares exijam decisões que não ignorem determinadas especificidades contextuais.

Então, se algo pode ser criticado em Warren é a forma como ela concebe uma ética do cuidado, o que leva a críticas dirigidas a um determinado modo de conceber a ética do cuidado, enquanto uma abordagem pautada em uma espécie de sensibilidade de certos grupos humanos que torna esse tipo de cuidado inadequado à exigência de imparcialidade na ética. Ou seja, não há um fundamento suficiente para ir além do relativismo e perceber quando o cuidado é também base para a manutenção de fontes de exploração em certos contextos sociais. Em outras palavras, ao tratar o cuidado como sensibilidade, ligada meramente a sentimentos e emoções morais, falta definir de que modo o cuidado pode ser combinado com um princípio para analisar quando o cuidado relativo a uma cultura ou praticado em uma 
sociedade é perpassado por erros e equívocos.

Ao mesmo tempo, para atender as reivindicações das teóricas feministas e ecofeministas de valorização do cuidado em uma teoria moral, pode-se pensar em definir o que é o cuidado para além de uma sensibilidade, exigindo que se torne uma habilidade a ser desenvolvida por todas os agentes morais: cuidado é uma atitude responsável que visa incrementar o bem-estar ou o modo de vida singular de um ser, ou de um grupo, considerando-se seus desejos, necessidades e interesses manifestos na condição de vulnerabilidade. Para tanto, recorre-se à contribuição de Torralba i Roselló e de Dall'Agnol sobre o conceito de cuidado. ${ }^{5}$ Ao se definir o que é o cuidado, tem-se um parâmetro universal e imparcial para avaliar as ações de cuidado com o elemento central da vulnerabilidade. A condição de vulnerabilidade de todos os implicados em um determinada situação do cuidado precisa ser igualmente relevante. Por isso, a vulnerabilidade é um critério fundamental para determinar a imparcialidade das ações em cada uma das esferas de relações de cuidado, garantindo que todos sejam atendidos de forma equitativa em suas necessidades de cuidado. Mas o outro com o qual se dá o comprometimento moral, nunca é um outro universal nem abstrato, é sempre uma pessoa única, singular, com uma história própria um modo de vida e um bem-estar que the é próprio, com necessidades e desejos específicos. Isso sim é um aspecto universal e inegável: o fato de cada sujeito à moralidade ser um ente singular e ter um direito à existência e a realização de suas particularidades tanto quanto qualquer outro. Isso torna o agente moral obrigado a auxiliar na realização desse bem-estar, ainda que não tenha uma relação de grande proximidade com o outro. Dentro de um círculo de relações expandido, ambos compartilham de uma comunidade, sociedade, ambiente, mundo. Cabe ao agente moral, portanto, agir de forma a proteger a vida do outro e contribuir para que possa ter sua individualidade garantida.

Todavia, mesmo com a adoção de uma perspectiva universal, o julgamento moral não precisa abrir mão da contextualização, da observação do outro como um ser concreto e dos detalhes das relações dos envolvidos, a fim de superar as críticas

5 Torralba i Roselló admite a polissemia de significado do termo 'cuidado', mas recebe a definição de Leininger: "ato de assistência, de apoio ou facilitação ao outro indivíduo, ou grupo, com necessidades evidentes ou antecipadas, para melhorar sua condição humana ou seu modo de vida" (LEININGER apud TORRALBA i ROSELLÓ, 2009, p. 115). Dall'Agnol define o cuidado como "um incremento do bem-estar do outro, baseado na simpatia, porque isso é bom para o indivíduo vulnerável" (DALL'AGNOL, 2012, p. 137).

R. Inter. Interdisc. INTERthesis, Florianópolis, v.12, n.1, p.16-41, Jan-Jun. 2015 
aos princípios da moralidade tradicional por sua abstração e, por muitas vezes, sequer poderem auxiliar o agente moral a decidir sobre uma determinada situação. Ademais, é possível então situar essa noção de cuidado na forma de um princípio universalizável: "aja de tal forma que tuas ações reflitam a habilidade do cuidado responsável para com aqueles que se encontram em relação contigo, atendo-se à singularidade de sua forma de vida e às particularidades para a promoção de seu bem-estar". 6 A condição de vulnerabilidade de todos os implicados em um determinada situação do cuidado precisa ser igualmente relevante. Por isso, a vulnerabilidade é um critério fundamental para determinar a imparcialidade das ações em cada uma das esferas de relações de cuidado, garantindo que todos sejam atendidos de forma equitativa em suas necessidades de cuidado.

Mas defender o princípio do cuidado universalizável significa já ir além da abordagem da ética sensível ao cuidado, buscando superar os possíveis comprometimentos relativistas da ética de Warren, quando se procura estabelecer uma proposta complementar entre a habilidade de cuidar e a defesa de um princípio universalmente válido. Tal relação, isto é, de como o cuidado pode manter seu caráter contextual e particular e, ao mesmo tempo, ser combinado com princípios universais não fica suficientemente esclarecido em Warren, o que leva ao risco do relativismo cultural.

\section{CONSIDERAÇÕES FINAIS}

A ética sensível ao cuidado de Warren, tal qual outras propostas oriundas da filosofia ecofeminista, busca romper as limitações imbricadas em concepções de ética animal e ambiental, normalmente elaboradas por filósofos homens contemporâneos, que não possuem a lente de gênero. O ecofeminismo, embora se expresse de diversas maneiras, tem o comprometimento de abolir o especismo e todas as outras formas de discriminação, seja contra humanos ou não humanos, enfocando como as diferentes formas de exploração e dominação se cruzam na

\footnotetext{
${ }^{6}$ Para uma leitura detalhada do que é o cuidado moralmente aplicável em diferentes situações e quais as consequências do princípio universalizável do cuidado, bem como o modo como ele é complementar a uma noção de justiça e de direitos tendo em vista a superação do monismo ético, conferir: KUHNEN, Tânia Aparecida. O princípio universalizável do cuidado: superando limites de gênero na teoria moral. Florianópolis, 2015. 383 f. Tese (Doutorado em Filosofia) - Centro de Filosofia e Ciências Humanas, Universidade Federal de Santa Catarina.
}

R. Inter. Interdisc. INTERthesis, Florianópolis, v.12, n.1, p.16-41, Jan-Jun. 2015 
sociedade e sustentam uma a outra. Por isso, a filosofia feminista não deve se comprometer só com o fim da exploração das mulheres e outros grupos de humanos vulneráveis, mas também com todos os dualismos que dão forma e justificam a exploração dos animais não humanos e da natureza em sua totalidade na sociedade patriarcal.

Nesse sentido, Warren entende que as éticas ambientais que mantêm a pretensa neutralidade de gênero não são suficientes para superar a dominação que os humanos exercem sobre os não humanos. Se existe uma lógica da dominação presente em todas as formas de discriminação, então uma ética que incorre também no machismo não é adequada. Para Warren, é preciso olhar para os contextos e perspectivas locais de forma sensível com o fim de desenvolver condutas morais adequadas. Uma ética sensível ao cuidado e a outros valores comumente deixados de lado nas teorias tradicionais, como a amizade e a empatia, pode dar conta dos aspectos mais contextuais de uma concepção moral. Dessa maneira, Warren se aproxima do biorregionalismo proposto por Gary Snyder, segundo o qual os limites estabelecidos pelo viés político do Estado nacional vão de encontro ao valor inerente dos povos nativos, dos membros de uma comunidade e de suas biorregiões. Por isso, uma perspectiva política local deve ter prioridade para reconhecer o devido valor das interações culturais e ambientais locais. Entretanto, à luz da vulnerabilidade como critério de considerabilidade moral, tanto o biorregionalismo quanto a ética sensível ao cuidado podem não ser considerados genuinamente ambientais, por não estabelecerem claramente qual o critério moral adequado e, por conseguinte, não cumprirem as exigências de universalidade, generalidade e imparcialidade.

A abordagem teórica ecofeminista de Warren, em outras palavras, pode não ser considerada uma ética ambiental genuína, ou seja, que é pautada por um critério claro de considerabilidade moral e um sistema normativo com um princípios ou conjunto de regras gerais, imparciais e universais, à medida que se aproxima do biorregionalismo de Gary Snyder e não esclarece de que modo se se deve atribuir considerabilidade aos animais individualmente. Além disso, ao recorrer à perspectiva holista de Aldo Leopold, Warren parece não distinguir suficientemente entre o valor moral de animais e rios, uma vez que aqueles são seres com um bem que thes é próprio, que buscam se realizar a seu próprio modo, independentemente de seu 
valor relativo à comunidade biótica ou ao ecossistema a que pertencem. É um valor que também independe da relevância de tal forma de vida para uma determinada população regional.

Embora a reivindicação de teóricas feministas e ecofeministas quanto à valorização de outros aspectos nas relações morais, entre eles o do cuidado, com o fim de ir além das limitações do monismo ético das concepções comprometidas com a sociedade patriarcal, seja fundamental, isso não é suficiente para garantir que o cuidado não seja perpassado por erros. Por isso, outro problema da perspectiva da ética sensível ao cuidado de Warren é o modo como entende o cuidado: uma sensibilidade ligada à certos sujeitos e cuja aplicação depende da análise da situação contextual. Com isso, falta a Warren um critério moral para avaliar quando até mesmo as ações de cuidado que ocorrem de forma específica em certos contextos são moralmente erradas, por exemplo, o critério da vulnerabilidade. Ademais, mesmo que a autora abra espaço para princípios morais, não fica claro de que forma se estabelece a relação entre esses princípios e sua concepção de sensibilidade ao cuidado contextual, o que termina por não afastar o risco do relativismo e parcialidade nas ações morais.

R. Inter. Interdisc. INTERthesis, Florianópolis, v.12, n.1, p.16-41, Jan-Jun. 2015 


\title{
KAREN WARREN'S ECOFEMINIST ETHICS: IS IT A MODEL OF GENUINE ENVIRONMENTAL ETHICS?
}

\begin{abstract}
Karen J. Warren presents an ecofeminist ethical perspective, according to which contextual aspects must be considered in the analysis of moral problems and moral situations. Therefore, she rejects the ethical monism of the main animal ethics theories. The aim of this article is to demonstrate, in the light of the notion of vulnerability (proposed as a criterion for moral considerability by Paul Taylor), that Warren's care-sensitive ethics cannot be considered as a genuine environmental ethical theory. It rather comes near Gary Snyder's bioregionalism and does not explain in which way a moral consideration is attributed to individual animals. In addition, the article seeks to analyze her possible moral relativism: according to the criteria of James Rachels and Peter Singer, Warren's proposal does not seem to meet the requirements of an impartial and general ethical theory, and may submit the problems of relativism since her conception of care is limited.
\end{abstract}

Keywords: Bioregionalism. Care. Environmental Ethics. Ecofeminist Philosophy. Moral Relativism.

\section{LA ÉTICA ECOFEMINISTA DE KARREN WARREN: UN MODELO DE ÉTICA AMBIENTAL GENUINA?}

\section{Resumen}

Karen J. Warren presenta una propuesta ética ecofeminista, según la cual los contextos necesitan ser tomados en consideración en el análisis de situaciones y problemas morales, rechazándose el monismo ético de las corrientes principales de la ética animal. El objetivo del presente artículo es mostrar, a la luz de la noción de vulnerabilidad, criterio de considerabilidad moral propuesto por Paul Taylor, que la ética sensible al cuidado propuesta por Warren no puede ser considerada una ética ambiental genuina, pues se aproxima del biorregionalismo de Gary Snyder y no esclarece de qué manera la consideración moral es atribuida a los animales individualmente. Al analizarse la cuestión del relativismo moral, según los criterios de James Rachels y Peter Singer, la propuesta de Warren parece no cumplir con los requisitos de una ética imparcial y general, y puede incurrir en los problemas del relativismo, una vez que la concepción de cuidado de la autora es limitada.

Palabras clave: Biorregionalismo. Cuidado. Ética ambiental. Filosofía ecofeminista. Relativismo moral. 


\section{REFERÊNCIAS}

CALLICOTT, J. Baird. Animal Liberation: A Triangular Affair. Environmental Ethics, Georgia, v. 2, n. 4, p. 311-338, Winter, 1980.

DALL'AGNOL, Darlei. Cuidar e respeitar: atitudes fundamentais na bioética.

Revista Bioethikos, Centro Universitário São Camilo, n. 2, v. 6, p. 133-146, 2012. FAHRI NETO, Leon. Concepções filosóficas ambientalistas. Ethic@. v. 5, n. 3, jul. 2006. p. 33-56.

FELIPE, Sônia T. Da considerabilidade moral dos seres vivos: a bioética ambiental de Kenneth E. Goodpaster. Ethic@. v. 5, n. 3, jul. 2006, p. 105-118.

KUHNEN, Tânia Aparecida. O princípio universalizável do cuidado: superando limites de gênero na teoria moral. Florianópolis, 2015. 383 f. Tese (Doutorado em Filosofia) - Centro de Filosofia e Ciências Humanas, Universidade Federal de Santa Catarina, Florianópolis.

NEGRÃO, Silvio Luiz. Biorregionalismo, ética e justiça ambiental. Ethic@. v. 5, n. 3, jul. 2006, p. 185-193.

PLUMWOOD, Val. Nature, Self, and Gender: Feminism, Environmental Philosophy, and the Critique of Rationalism. In: ZIMMERMANN, Michael et all (Orgs.) Environmental Philosophy. Upper Saddle River: Prentice Hall, 1998, p. 291314.

RACHELS, James. Os elementos da filosofia moral. 4 ed. Barueri: Manole, 2006. ROSENDO, Daniela. Ética sensível ao cuidado: alcance e limites da filosofia ecofeminista de Warren. Florianópolis, 2012. 153 f. Dissertação (Mestrado em Filosofia) - Centro de Filosofia e Ciências Humanas, Universidade Federal de Santa Catarina, Florianópolis.

SINGER, Peter. Ética prática. Trad. Jefferson Luiz Camargo. 3. ed. São Paulo: Martins Fontes, 2002.

SHAFER-LANDAU, Russ. The Fundamentals of Ethics. 2. ed. Oxford: Oxford University Press, 2012. 
SNYDER, Gary. The Place, the Region and the Commons. In: SNYDER, Gary. The Gary Snyder Reader: Prose, Poetry, and Translations. Cidade: Counterpoint, 1999, p. 183-199.

TAYLOR, Paul. Respect for Nature: a Theory of Environmental Ethics. 2 ed. Princeton: Princeton University Press, 1989.

TORRALBA i ROSELLÓ, Francesc. Antropologia do cuidar. Trad. Guillerme Laurito Summa. Petrópolis: Vozes, 2009.

WARREN, K. J. Ecofeminist Philosophy: a Western Perspective on What It Is and Why It Matters. Rowman \& Littlefield Publishers, 2000.

Artigo:

Submetido em 04.05.2015

Aceito em 01.06.2015 